with ischaemic heart disease implies return to work without loss of status or earnings: when this is not possible advice about future employment should be available from social workers and disablement resettlement officers. About half of patients fail to return to work after an infarct, ${ }^{2}$ and there is no apparent benefit from exercise training or social advice. ${ }^{3}$

Factors other than physical disability may influence the decision of patients not to return to work, but breathlessness and angina are among the most important. ${ }^{4}$ Fears about precipitating a further infarct and general weakness may contribute to the low number of successfully rehabilitated patients. ${ }^{4}$ A study of 84 patients in work at the time of infarction supports this hypothesis. ${ }^{5}$ The $17^{\circ}$ of patients unemployed one year after infarction showed greater psychiatric morbidity, but it was not clear whether this was due to delayed return to work or inability to resume work because of angina and breathlessness.

We found that after a myocardial infarction a quarter of men in full time employment may expect to be either sacked or convalescent for at least six months. Programmes of education and rehabilitation for patients should provide guidance about work, and when employment is ended prematurely alternative occupations should be suggested. Quality of life is as important as its duration.

We thank the consultant physicians at the Royal Gwent Hospital for permission to conduct this study.

'Jenkins B, Mayberry JF, Kent SV, Colbourne G. Patients' evaluation of a post-myocardial infarction teaching programme administered by nurses. Postgrad Med $\mathcal{F}$ (in press).

- Pell S, D'Alonso CA. Immediate mortality and five year survival of employed men with a first myocardial infarct. $N$ Engl f Med 1964; $\mathbf{2 7 0}: 915$.

${ }^{3}$ Mayou R, MacMahon D, Sleight P, Florencio MJ. Early rehabilitation after myocardial infarction. Lancet 1981;ii:1399-1401.

' Cay EL, Vetter N, Philip A, Dugard P. Return to work after a heart attack. If Psychosom Res 1973;17:231-43.

${ }^{3}$ Lloyd GG, Cawley RH. Psychiatric morbidity after a myocardial infarction. $Q \mathcal{F}$ Med 1982;51:33-42.

(Accepted 1 fuly 1983)

Royal Gwent Hospital, Newport, Gwent

J F MAYBERRY, MD, MRCP, medical registrar

S V KENT, SRN, RSCN, nursing officer

B JENKINS, SRN, coronary care unit sister

G COLBOURNE, clerk

Correspondence to: Dr J F Mayberry.

\section{Comparison of accuracy of digital and standard mercury thermometers}

An increasing amount of advanced, electronic hardware is becoming available for use in medical practice. Its superiority over traditional equipment is sometimes accepted by the medical and nursing professions without adequate evaluation.

Several electronic thermometers have recently been marketed. Manufacturers suggest that these thermometers have assured accuracy and that they require less attention to technique. ${ }^{12}$ This echoes the claim that automated sphygmomanometers would eliminate human observer error and thus be more accurate, which has not been substantiated. ${ }^{3}$ Further advantages claimed for digital readout thermometers include ease of reading, shorter time spent taking the temperature, disposable probes that prevent cross infection, and durability. ${ }^{2}$ Are the advantages over conventional thermometers sufficiently great to justify the introduction of such expensive equipment into an underfunded state health service or a developing country? If the claim regarding the greater accuracy of electronic thermometers could be upheld then the case for their more widespread introduction would be stronger. Our study examined this question.

\section{Method and results}

Three different types of thermometer (IVAC 821 (IVAC Corporation, San Diego, California 92121 USA); Electromedia Mark V (Electromedics,
Denver, Colorado, USA); and standard mercury thermometer) were compared on 20 inpatients. All thermometers were carefully checked and standardised before the study and rechecked on its completion. Their calibration was found to be unchanged. The three thermometers were simultaneously placed under the tongue and the temperature recorded after two minutes. One hundred consecutive triple readings were recorded and analysed (table). Pairs of readings were compared.

Comparison of readings obtained with two digital thermometers (IVAC and Electromedia) and standard mercury thermometer in 20 patients

\begin{tabular}{lccc}
\hline & $\begin{array}{c}\text { IVAC } \\
v \\
\text { standard }\end{array}$ & $\begin{array}{c}\text { Standard } \\
v \\
\text { Electromedia }\end{array}$ & $\begin{array}{c}\text { Electromedia } \\
v \\
\text { IVAC }\end{array}$ \\
\hline No of comparisons & 100 & 100 & 100 \\
Mean difference ( & & 0.026 \\
SD of difference & 0.008 & 0.018 & 0.026 \\
Z value of mean difference & 0.341 & 0.296 & 0.340 \\
Significance of mean difference & 0.2 & 0.4 & 0.5 \\
& $\mathrm{p}>0.1$ & $\mathrm{p}>0.1$ & $\mathrm{p}>0.1$ \\
\hline
\end{tabular}

The mean difference between each pair was: $0.026^{\circ} \mathrm{C}$ between the Electromedia and the IVAC; $0.018^{\circ} \mathrm{C}$ between the standard thermometer and the Electromedia; and only $0.008^{\circ} \mathrm{C}$ between the IVAC and the standard thermometer. These were the averages of positive and negative differences and indicate that all three thermometers produced similar results. The consistency of the paired differences may be measured by their standard deviations. All three comparisons had standard deviations of the order of only $0.3^{\circ} \mathrm{C}$.

This study was not conducted blind. Therefore, the possibility of observer bias required evaluation. In all non-randomised, non-digital measurement systems there is an inherent bias towards certain terminal digits and away from others. The most commonly preferred digits are 0 and 5 and the most avoided are 1 and 9 (both rounded to 0 ). ${ }^{4}$ The distributions of the two digital thermometers were first tested to see whether they differed significantly from the uniform distribution. Neither thermometer's reading was significantly different from the expected distribution $(p>0.1$ for both thermometers). The results obtained with the standard thermometer, however, were appreciably different from the uniform distribution $(p=0.002)$ with the expected preference for 0 and 5 . These findings support the hypothesis that observer bias did not produce the concordance between the results obtained with the standard and with the digital thermometers.

\section{Comment}

This study produced no significant differences between the readings given by standard mercury thermometers and electronic thermometers in a typical ward of a general hospital. We are currently investigating whether these findings hold true at extremes of temperatures.

Greater accuracy has been one of the more persuasive arguments in favour of the electronic thermometer but is rendered untenable by the results of this study. Mercury thermometers have the advantage that they are familiar, inexpensive, lightweight, and compact in size and do not require recurrent expenditure on recharging, replacement of probes, and servicing. We conclude that the mercury thermometer should not be displaced from its traditional and well deserved place in the general practitioner's pocket and the hospital ward.

We thank the nursing staff of the rehabilitation unit, Riyadh Armed Forces Hospital, for their help and cooperation.

1 IVAC Corporation. Electronic thermometer information sheet. IVAC 811. (Form No 60-73-12, ref 9/73.) (IVAC Corporation, 11353 Sorrento Valley Road, San Diego, California 92121 USA).

2 Electromedics Inc. Mark V Electronic Thermometry System information sheet. (Electromedics Inc, PO Box 1051, Denver, Colorado 80201 USA.)

${ }^{3}$ Honyor SN, Flynn JM, Cochinears C. Comparison of performance of various sphygmomanometers with intra-arterial blood-pressure readings. Br Med F 1978;ii:159-62.

4 Ehrenberg ASC. Elements of numeracy. Fournal of the Royal Statistical Society $A$ 1977;140:277-97.

(Accepted 28 fune 1983)

Riyadh Al Kharj Hospital Programme, Riyadh 11159, Kingdom of Saudi Arabia

N J SHANKS, MB, MRCGP, consultant in rehabilitation medicine

A LAMBOURNE, PHD, FSS, statistician

C MORTON, MB, CHB, senior house officer in rehabilitation medicine

JOHN R A SANFORD, MB, MRCP, senior consultant in rehabilitation medicine

Correspondence to: Dr N J Shanks. 